\title{
Effect of valproic acid on cisplatin-resistant ovarian cancer cell lines
}

\author{
Somayeh Hashemi-Sheikhshabani ${ }^{1}$, Zeinab Amini-Farsani ${ }^{2}$, Mehdi Shamsara ${ }^{3}$, Zahra Sajadpoor ${ }^{1}$, Mohammad Hossein \\ Sangtarash ${ }^{4}$, Hossein Teimori ${ }^{*}$ \\ ${ }^{1}$ Cellular and Molecular Research Center, Basic Health Sciences Institute, Shahrekord University of Medical Sciences, \\ Shahrekord, Iran \\ ${ }^{2}$ Young Researchers and Elites Club, Shahrekord Branch, Islamic Azad University, Shahrekord, Iran \\ ${ }^{3}$ National Research Center for Transgenic Mouse, National Institute of Genetic Engineering and Biotechnology, Tehran, Iran \\ ${ }^{4}$ Department of Biology, University of Sistan and Baluchestan, Zahedan, Iran
}

*Corresponding Author: Hossein Teimori, Tel: +98-381-3346692, Fax: +98-381-3330709, Email: hteimori@skums.ac.ir

\begin{abstract}
Background and aims: Platinum resistance has been one of the most important problems in the management of ovarian cancer. The effects of various chemotherapeutic agents are limited in patients with platinum resistance. Therefore, developing new anticancer drugs that can improve the effect of currently used cytostatics is critical. The current study investigated the effects of valproic acid (VPA) alone and in combination with cisplatin on ovarian cancer cells.

Methods: In this experimental study, the human ovarian cancer cell lines (A2780-S and A2780-CP) were grown in RPMI-1640 medium in appropriate culture conditions. The cells were treated with various concentrations of cisplatin $(0.15-400 \mu \mathrm{g} / \mathrm{mL})$ or VPA $(10-2000 \mu \mathrm{g} / \mathrm{mL})$ and were incubated for 24,48 , and 72 hours. Moreover, A2780 cells were co-treated with different concentrations of cisplatin and VPA for 48 hours. Afterward, cell viability was investigated using MTT assay. GraphPad Prism statistical software was used for the data analysis and ANOVA and Duncan's test were conducted.

Results: A dose- and time-dependent reduction was observed in cell viability following the treatment with cisplatin or VPA. Moreover, cotreatment of the A2780 cells with cisplatin and VPA resulted in a significantly greater inhibition of cell viability compared to the treatment with either agent alone.

Conclusion: Overall, it can be argued that VPA does not only cause inhibition of proliferation and induction of apoptosis in ovarian cancer cells but also helps to enhance the antiproliferative effects of cisplatin and results in the increased susceptibility to cisplatin in resistant cells. VPA may therefore be used to treat cancer in the future.

Keywords: Ovarian cancer; Cisplatin; Valproic acid; Platinum resistance; Antiproliferative effect
\end{abstract}

Received: 30 April 2018, Accepted: 20 August 2018, ePublished: 14 May 2019

\section{Introduction}

Ovarian cancer is one of the most prevalent cancers worldwide and the first leading cause of death as a reproductive system cancer among women (1). The mainstay of treatment of ovarian cancer is cytoreductive surgery followed by chemotherapy. Cisplatin and its derivatives are widely used as chemotherapeutic agents for the treatment of various cancers, including ovarian cancer $(2,3)$. Accordingly, cisplatin and carboplatin are used for the treatment of ovarian cancer. Cisplatin, as an alkylating agent, binds to the N7-guanine to form intrastrand crosslink DNA adducts that can effectively prevent replication and transcription and induce apoptosis $(4,5)$.

Despite its high therapeutic potential, cisplatin is not widely used to treat ovarian cancer due partly to reduced intracellular drug accumulation, increased platinum-DNA adduct repair, and enhanced platinum-DNA damage tolerance that lead to intense side effects and development of cisplatin resistance in cancer cells $(2,6)$. Therefore, developing new anticancer drugs that can more specifically prevent the growth of ovarian cancer cells may improve the effect of currently used cytostatics and consequently increase survival rate, which is considered a critical issue in patients (6-8).

Valproic acid (VPA), a branched short-chain fatty acid, is mainly used to treat epilepsy and bipolar disorders. Recently, VPA has been widely studied for its anti-cancer effects in many cancers (9-11). In this regard, VPA induces cell cycle arrest, apoptosis, differentiation, and senescence. Moreover, it has been observed that VPA arrests tumor growth and increases the susceptibility of cancer cells to the therapeutic agents $(12,13)$. VPA exerts few toxic side effects and often is used as an adjuvant in combination with anticancer cytotoxic drugs. Therefore, the aim of this

(C) 2019 The Author(s); Published by Shahrekord University of Medical Sciences. This is an open-access article distributed under the terms of the Creative Commons Attribution License (http://creativecommons.org/licenses/by/4.0), which permits unrestricted use, distribution, and reproduction in any medium, provided the original work is properly cited. 
study was to investigate the anti-cancer activity of VPA in two ovarian cancer cell lines, A2780-S and A2780-CP, alone and in combination with cisplatin.

\section{Materials and Methods}

Cell culture reagents, including RPMI-1640 culture medium, penicillin-streptomycin, trypsin-EDTA, phosphate buffered saline (PBS), and fetal bovine serum (FBS) were purchased from Gibco Co. (Invitrogen, Carlsbad, CA, USA). MTT (3-(4, 5-dimethylthiazol-2yl)-2, 5-diphenyltetrazolium bromide) assay kit was also provided from BIO IDEA Co. (Tehran-Iran). Cisplatin and VPA were purchased from Sigma-Aldrich (St. Louis, MO, USA). Moreover, a stock solution of cisplatin (500 $\mu \mathrm{M})$ and VPA $(60 \mathrm{mM})$ was prepared in PBS immediately before use.

Furthermore, the human ovarian cancer cell lines (A2780-S and A2780-CP) were obtained from the National Cell Bank of Iran (NCBI), Pasteur Institute of Iran (NCBI, C461 and C454). A2780 cells were grown in RPMI-1640 supplemented with 10\% FBS and $1 \%$ penicillin/streptomycin incubated at $37^{\circ} \mathrm{C}$ with humidified air and 5\% CO2.

The viability of A2780 cells was measured by the MTT assay after the treatment with cisplatin, VPA, and their combination. Briefly, cancer cells were seeded into a 96well plate at 8000 cells/mL (A2780-CP) and 4000 cells/ $\mathrm{mL}$ (A2780-S) densities and incubated overnight. Next, the medium was discarded and the cells were treated with serial dilutions of either VPA or cisplatin in a fresh culture medium for 24, 48, and 72 hours. All concentrations were replicated 3-4 times. The cells that were left untreated were considered control. After the incubation, medium was removed, and $10 \mu \mathrm{L}$ of MTT in $100 \mu \mathrm{L}$ fresh medium was added to each well and incubated at $37^{\circ} \mathrm{C}$ for 4 hours. The medium with MTT was removed and MTT formazan crystals were solubilized in $150 \mu \mathrm{L}$ of DMSO, and absorbance of each well was measured at $570 \mathrm{~nm}$ using an ELISA reader (AWARENESS-State Fax, USA). The rate of cell viability was determined by the following formula (14):

Cell viability rate $(\%)=\mathrm{OD}$ of treated cells/OD of control cells $\times 100$

Each experiment was performed at least in triplicate. GraphPad Prism statistical software, version 5.01 (GraphPad, USA) was used for the data analysis, and analysis of variance (ANOVA) and Duncan's test were conducted. All data were presented as mean \pm standard deviation (SD). $P<0.05$ was considered statistically significant.

\section{Results}

In this stydy, the effect of cisplatin was investigated on two ovarian cancer cell lines, namely A2780-S and A2780$\mathrm{CP}$, at different time points (24, 48, and 72 hours). Our results showed that IC50 values in A2780-S cells at the abovementioned time points were $6.5,1.4$, and $0.67 \mu \mathrm{g} /$ $\mathrm{mL}$, respectively. Moreover, the IC50 values of cisplatin in A2780-CP cells were observed 25, 2.8, and $1.5 \mu \mathrm{g} / \mathrm{mL}$ at 24,48 , and 72 hours, respectively (Table 1, Figure 1).

Furthermore, the effect of VPA on A2780-S cells in different time points was examined. Our results showed a dose-dependent decrease in cell viability, suggesting that A2780-CP cells were more sensitive to VPA treatment (IC50 values $=1000,400,275 \mu \mathrm{g} / \mathrm{mL}$ ) than A2780-S cells (IC50 values $=1200,650,425 \mu \mathrm{g} / \mathrm{mL}$ ) in different time points (Figure 2, Table 1).

In addition, the investigation of A2780-S cells under different concentrations of cisplatin and VPA for 48 hours showed a more significant reduction of cell viability in combination therapy compared to monotherapy. The IC50 values were 0.12 and $1.2 \mu \mathrm{g} / \mathrm{mL}$ for cisplatin in A2780-S cells and A2780-CP cells, respectively. While, the IC50 of VPA was $400 \mu \mathrm{g} / \mathrm{mL}$ in A2780-S cells and $100 \mu \mathrm{g} / \mathrm{mL}$ in A2780-CP cells (Figure 3).

\section{Discussion}

The present study showed the effect of VPA (a histonedeacetylase inhibitor) on cisplatin-resistant ovarian cancer cell lines. Cisplatin is one of the most important anticancer compounds used in the first line of chemotherapy for the treatment of ovarian cancer (15). Resistance to chemotherapeuic drugs including cisplatin, is a hindrance to successful chemotherapy in the patients with ovarian cancer $(16,17)$. Therefor, new modalities are needed to overcome drug resistance $(17,18)$. VPA is a short chain fatty acid which is used in the treatment of various neurological disorders including seizures, bipolar disorder, and migraine (19). Recent studies have shown the anticancer effects of VPA $(20,21)$. In this study, first, the antiproliferative effects of cisplatin and VPA were compared at different time points and concentrations on two cell lines, A2780-S and A2780-CP, by the MTT assay. Then, different concentrations of both drugs were prepared to investigate the sensitizing effect of VPA on resistance to cisplatin.

The treatment of two cell lines of A2780-S and A2780CP with cisplatin and VPA at different time points (24, 48 , and 72 hours) indicated that the rate of cell viability was reduced in a time-dependent manner. The effect of

Table 1. IC50 of Cisplatin and VPA at Different Time Points

\begin{tabular}{lcc}
\hline & A2780-S $(\boldsymbol{\mu g} / \mathbf{m L})$ & A2780-CP $(\boldsymbol{\mu g} / \mathbf{m L})$ \\
\hline Cisplatin (24 h) & 6.5 & 25 \\
Cisplatin (48 h) & 1.4 & 2.8 \\
Cisplatin (72 h) & 0.67 & 1.5 \\
VPA (24 h) & 1200 & 1000 \\
VPA (48 h) & 650 & 400 \\
VPA (72 h) & 425 & 275 \\
\hline
\end{tabular}


A

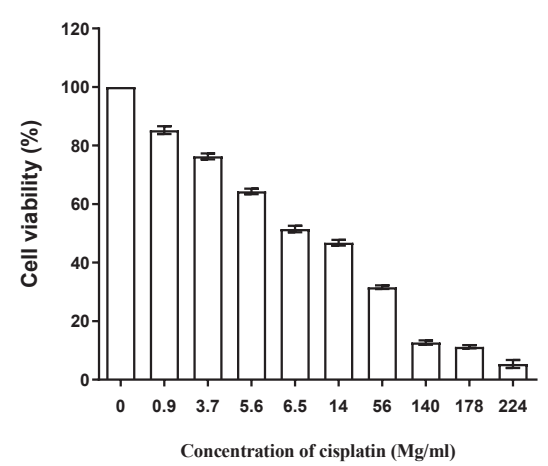

C

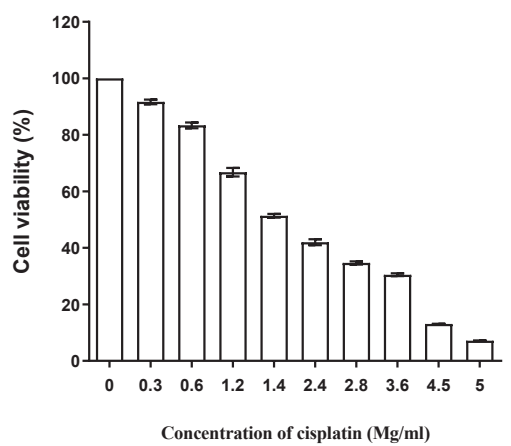

E

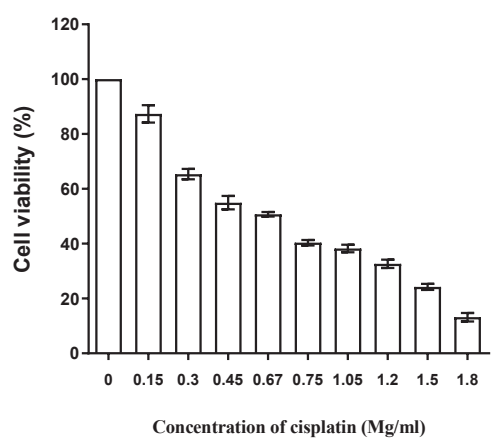

$\mathbf{A 2 7 8 0 / C P}$

B

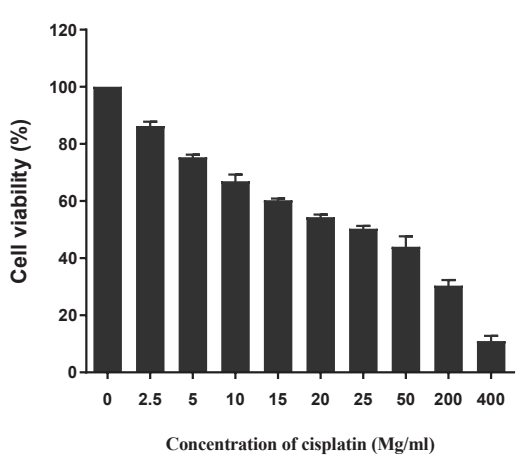

D

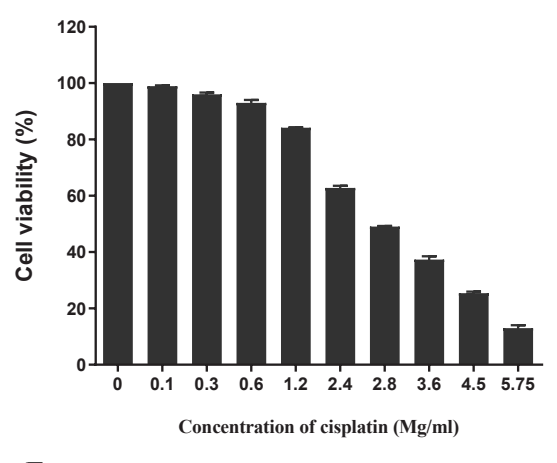

F

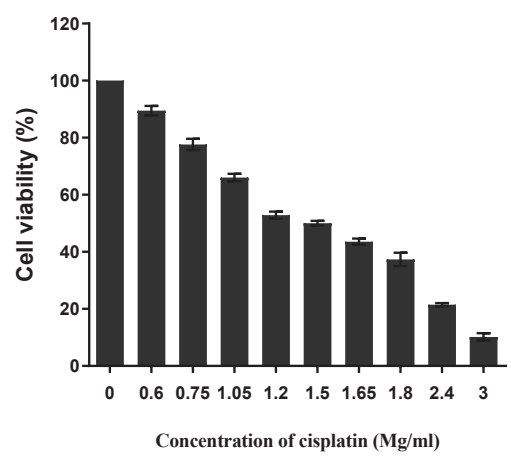

Figure 1. Growth of A2780-S and A22780-CP cells cultured in the presence of various concentrations of cisplatin after 24 (A, B), $48(\mathbf{C}, \mathbf{D})$, and 72 hours (E, F). Each bar represents the mean \pm standard deviation; $P<0.05$.

different concentrations of cisplatin was also assessed, the results of which showed a dose-dependent decrease in the cell viability. Cisplatin alone led to a significant reduction in cell survival at $0.15 \mu \mathrm{g} / \mathrm{mL}$ for A2780-S and $0.3 \mu \mathrm{g} / \mathrm{mL}$ for A2780-CP (Figures 1E, and 1D). A dose-dependent reduction in cell viability was also observed following the treatment with VPA. The lowest concentration of VPA that inhibited the cell growth was $10 \mu \mathrm{g} / \mathrm{mL}$ for both A2780-S and A2780CP cells, whereas $2000 \mu \mathrm{g} / \mathrm{mL}$ of VPA abolished ovarian cancer cells almost completely (Figure 2). Although cisplatin treatment resulted in a further reduction in A2780-S cell viability at 24,48 , and 72 hours (The IC50 values of cisplatin for A2780-S were 6.5, 1.4, $0.67 \mu \mathrm{g} / \mathrm{mL}$ and for A2780-CP were 25, 2.8, $1.5 \mu \mathrm{g} / \mathrm{mL}$, respectively) (Figure 1), we observed that A2780-CP cells were more sensitive to VPA treatment than A2780-S cells (The IC50 values of VPA for A2780-S were 1000, 400, $275 \mu \mathrm{g} / \mathrm{mL}$ and for A2780-CP were 1200, 650, $425 \mu \mathrm{g} /$ $\mathrm{mL}$, respectively) (Figure 2 ).

Furthermore, co-treatment of the A2780 cells with cisplatin and VPA for 48 hours resulted in a significantly greater inhibition of cell viability compared to the treatment with either agent alone. The co-treatment of A2780-S cells with $400 \mu \mathrm{g} / \mathrm{mL}$ VPA and $0.12 \mu \mathrm{g} / \mathrm{mL}$ cisplatin suppressed cell growth by $50 \%$. Moreover, the treatment of A2780-CP cells with the combination of 100 $\mu \mathrm{g} / \mathrm{mL}$ VPA and $1.2 \mu \mathrm{g} / \mathrm{mL}$ cisplatin decreased cell growth by $50 \%$ (Figure 3 ). Our results showed that VPA could sensitize even the drug-resistant cell lines and cause the inhibition of cell viability. 
A

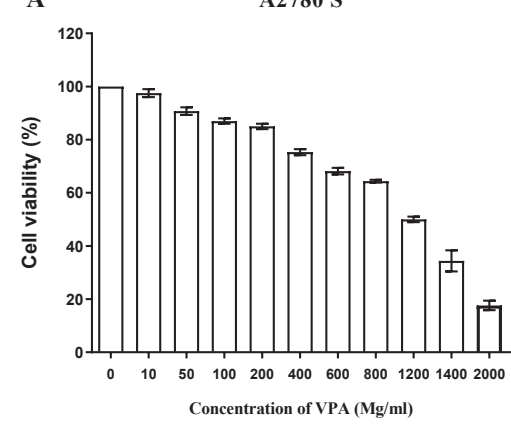

C

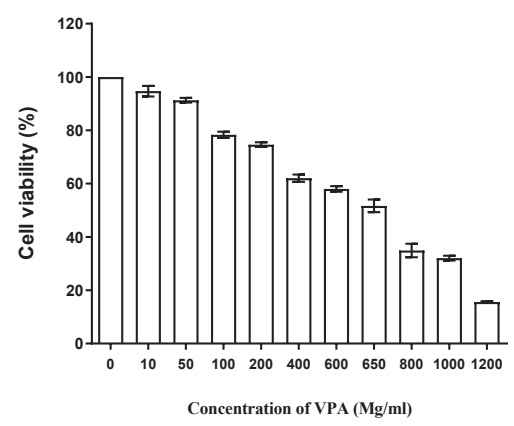

E

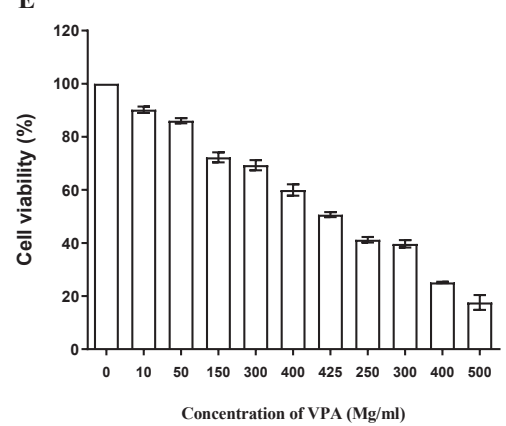

B

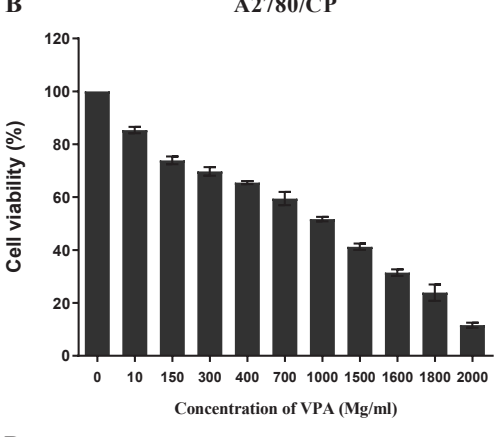

D

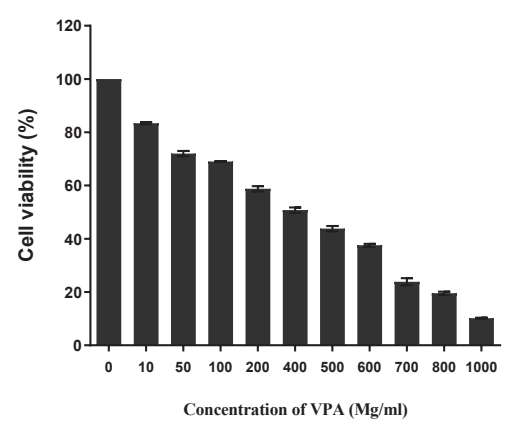

F

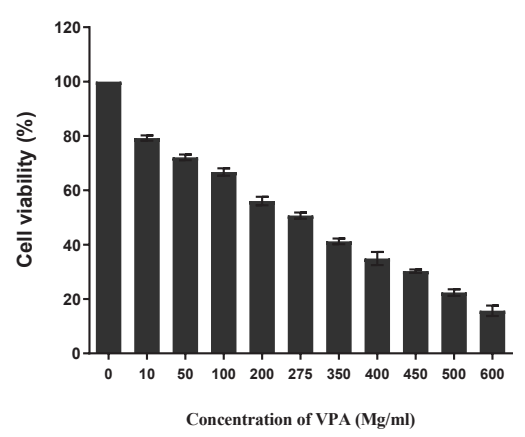

Figure 2. Growth of A2780-S and A22780-CP cells Cultured in the Presence of Various Concentrations of VPA After 24 (A, B), 48 (C, D), and 72 hours (E, F). Each bar represents the mean \pm standard deviation; $P<0.05$.

The findings of MTT assay regarding the effect of cisplatin in inhibiting the growth of A2780 cancer cells demonstrated that certain concentrations of this drug could significantly inhibit the growth of cancer cells, to such a degree that higher concentrations of cisplatin had a higher ability to kill the cells. Given that most routinely used chemotherapy drugs are cytotoxic, they may damage normal cells of the body and cause adverse side effects (20). A strategy to resolve this problem is the use of chemotherapy drugs alongside the drugs already approved for treating non-cancer diseases with widely known toxicity. A group of these drugs are anticonvulsants including VPA. VPA has attracted much attention due to its inhibitory effects on the proliferation, invasion, migration, and angiogenesis of cancer cells (22). The present study demonstrated that VPA could decrease the viability of ovarian cancer cells in a dose-dependent manner. The antiproliferative activity of VPA has already been confirmed on a wide spectrum of cell lines including leukemia (23), melanoma (24), lung cancer (25), breast cancer (26), prostate cancer (27), and gastric carcinoma (28).

Besides, VPA renders the improvement of efficacy of chemotherapy drugs such as cisplatin. Likewise, in the present study, VPA enhanced the cisplatin-induced growth inhibitory effect in the cells under this study. The results of MTT assay indicated that co-treatment of ovarian cancer cells with VPA and cisplatin caused a decrease in the cisplatin concentration required to reach the IC50. When VPA and cisplatin are used simultaneously, cell death increases particularly in the cisplatin-resistant cell lines. This suggests that VPA may increase the susceptibility of ovarian cancer cells to induce apoptosis. The findings on the effect of combined cisplatin and VPA on melanoma (15) and larynx (29) cancer cell lines are consistent with the results of our study.

\section{Conclusion}

According to the findings of this study, it can be argued 

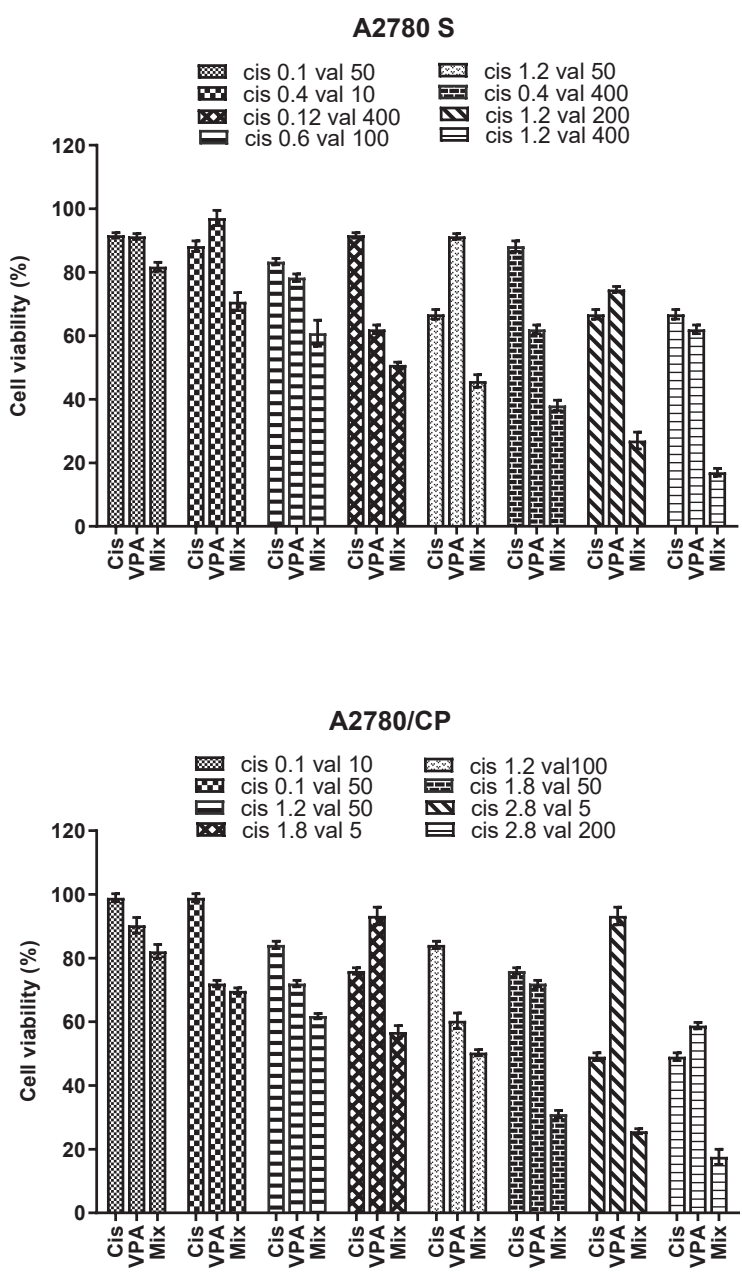

Figure 3. Growth of A2780-S and A2780-CP Cells Cultured in the Presence of Various Concentrations of VPA and Cisplatin After 48 hours. Each bar represents the mean \pm standard deviation; $P<0.05$.

that VPA can cause the inhibition of proliferation and induction of cell death in A2780 cancer cell lines. The antiproliferative activity is also dose- and time- dependent. Moreover, VPA can enhance the antiproliferative effects of cisplatin, and result in the increased susceptibility in the cisplatin-resistant cells. Taken together, the findings support that treatment with VPA can lead to an increased susceptibility to cisplatin in ovarian cancer cells and enhance the efficacy of chemotherapeutic agents. VPA can be therefore recommended as a useful drug in cancer therapy. However, further studies are required to determine the precise rate of apoptosis using qualitative techniques such as flow cytometry.

Conflict of interests

None.

Ethical considerations

This experimental study was approved by the Ethics Committee of Shahrekord University of Medical Sciences (ethical code: IR.SKUMS.REC.1394.128).

Acknowledgments

This study was funded by the Research and Technology Deputy of
Shahrekord University of Medical Sciences (Research Grant: 1931).

References

1. Gamarra-Luques CD, Goyeneche AA, Hapon MB, Telleria $\mathrm{CM}$. Mifepristone prevents repopulation of ovarian cancer cells escaping cisplatin-paclitaxel therapy. BMC Cancer. 2012;12:200. doi: 10.1186/1471-2407-12-200.

2. Wang J, Wu GS. Role of autophagy in cisplatin resistance in ovarian cancer cells. J Biol Chem. 2014;289(24):17163-73. doi: 10.1074/jbc.M114.558288.

3. Akbarzadeh S, Ebrahimi F, Faghih Z, Movahed A, Faghih Z. Cytotoxic effect of two novel platinum (II) complexes on breast cancer: an in vitro study. Asian Pac J Cancer Biol. 2018;3(2):47-50. doi: 10.22034/APJCB.2018.3.2.47.

4. Sundquist WI, Lippard SJ. The coordination chemistry of platinum anticancer drugs and related compounds with DNA. Coord Chem Rev. 1990;100:293-322. doi: 10.1016/00108545(90)85013-I.

5. Dutta S, Rivetti C, Gassman NR, Young CG, Jones BT, Scarpinato K, et al. Analysis of single, cisplatin-induced DNA bends by atomic force microscopy and simulations. J Mol Recognit. 2018;31(10):e2731. doi: 10.1002/jmr.2731.

6. Hu G, Zhang J, Xu F, Deng H, Zhang W, Kang S, et al. Stomatinlike protein 2 inhibits cisplatin-induced apoptosis through MEK/ERK signaling and the mitochondrial apoptosis pathway in cervical cancer cells. Cancer Sci. 2018;109(5):1357-68. doi: 10.1111/cas.13563.

7. Helm CW, States JC. Enhancing the efficacy of cisplatin in ovarian cancer treatment - could arsenic have a role. J Ovarian Res. 2009;2:2. doi: 10.1186/1757-2215-2-2.

8. Johnson SW, Stevenson J, O'Dwyer P, DeVita V, Hellman S, Rosenberg S. Cisplatin and its analogues. In: Cancer: Principles and practice of oncology. 6th ed. Lippincott Williams \& Wilkins; 2001:377-88.

9. Tsai C, Leslie JS, Franko-Tobin LG, Prasnal MC, Yang T, Vienna Mackey L, et al. Valproic acid suppresses cervical cancer tumor progression possibly via activating Notch1 signaling and enhances receptor-targeted cancer chemotherapeutic via activating somatostatin receptor type II. Arch Gynecol Obstet. 2013;288(2):393-400. doi: 10.1007/s00404-013-2762-7.

10. Sun L, Coy DH. Anti-convulsant drug valproic acid in cancers and in combination anti-cancer therapeutics. Mod Chem Appl. 2014;2(1):1-5. doi: 10.4172/2329-6798.1000118.

11. Eckschlager T, Plch J, Stiborova M, Hrabeta J. Histone Deacetylase Inhibitors as Anticancer Drugs. Int J Mol Sci. 2017;18(7). doi: 10.3390/ijms18071414.

12. Gan CP, Hamid S, Hor SY, Zain RB, Ismail SM, Wan Mustafa WM, et al. Valproic acid: growth inhibition of head and neck cancer by induction of terminal differentiation and senescence. Head Neck. 2012;34(3):344-53. doi: 10.1002/ hed.21734.

13. Chiou HY, Lai WK, Huang LC, Huang SM, Chueh SH, $\mathrm{Ma} \mathrm{HI}$, et al. Valproic acid promotes radiosensitization in meningioma stem-like cells. Oncotarget. 2015;6(12):995969. doi: 10.18632/oncotarget.3692.

14. Thotala D, Karvas RM, Engelbach JA, Garbow JR, Hallahan AN, DeWees TA, et al. Valproic acid enhances the efficacy of radiation therapy by protecting normal hippocampal neurons and sensitizing malignant glioblastoma cells. Oncotarget. 2015;6(33):35004-22. doi: 10.18632/oncotarget.5253.

15. Chodurek E, Orchel A, Gruchlik A, Aleksander E, Golabek K, Dzierzewicz Z. Valproic acid enhances cisplatin cytotoxicity in melanoma cells. Acta Pol Pharm. 2012;69(6):1298-302.

16. Kigawa J. New strategy for overcoming resistance to chemotherapy of ovarian cancer. Yonago Acta Med. 2013;56(2):43-50. 
17. Baez-Vega PM, Valiyeva F, Santiago G, Vivas-Mejia P. The role of RBPMS in cisplatin resistant ovarian cancer. Washington, DC: AACR; 2017.

18. Matsuura K, Huang NJ, Cocce K, Zhang L, Kornbluth S. Downregulation of the proapoptotic protein MOAP-1 by the UBR5 ubiquitin ligase and its role in ovarian cancer resistance to cisplatin. Oncogene. 2017;36(12):1698-706. doi: 10.1038/ onc.2016.336.

19. Henry TR. The history of valproate in clinical neuroscience. Psychopharmacol Bull. 2003;37 Suppl 2:5-16.

20. Callejo A, Sedo-Cabezon L, Juan ID, Llorens J. CisplatinInduced Ototoxicity: Effects, Mechanisms and Protection Strategies. Toxics. 2015;3(3):268-93. doi: 10.3390/ toxics3030268.

21. Hajikazemi M, Sohrabi H, Yamchi A, Saeedi M. The effects of valproic acid on the mRNA expression of Natriuretic Peptide Receptor A and KQT-like subfamily Q-1 in human colon cancer cell lines. Alex J Med. 2018;54(1):17-22. doi: 10.1016/j.ajme.2017.04.002.

22. Yagi Y, Fushida S, Harada S, Kinoshita J, Makino I, Oyama K, et al. Effects of valproic acid on the cell cycle and apoptosis through acetylation of histone and tubulin in a scirrhous gastric cancer cell line. J Exp Clin Cancer Res. 2010;29:149. doi: 10.1186/1756-9966-29-149.

23. Zhao X, Yang W, Shi C, Ma W, Liu J, Wang Y, et al. The G1 phase arrest and apoptosis by intrinsic pathway induced by valproic acid inhibit proliferation of BGC-823 gastric carcinoma cells.
Tumour Biol. 2011;32(2):335-46. doi: 10.1007/s13277-0100126-5.

24. Valentini A, Gravina P, Federici G, Bernardini S. Valproic acid induces apoptosis, p16INK4A upregulation and sensitization to chemotherapy in human melanoma cells. Cancer Biol Ther. 2007;6(2):185-91.

25. Shao N, Zou J, Li J, Chen F, Dai J, Qu X, et al. Hyperactivation of WNT/beta-catenin signaling pathway mediates anti-tumor effects of histone deacetylase inhibitors in acute T lymphoblastic leukemia. Leuk Lymphoma. 2012;53(9):176978. doi: 10.3109/10428194.2012.663085.

26. Platta CS, Greenblatt DY, Kunnimalaiyaan M, Chen H. Valproic acid induces Notch1 signaling in small cell lung cancer cells. J Surg Res. 2008;148(1):31-7. doi: 10.1016/j.jss.2008.03.008.

27. Fortunati N, Bertino S, Costantino L, Bosco O, Vercellinatto I, Catalano MG, et al. Valproic acid is a selective antiproliferative agent in estrogen-sensitive breast cancer cells. Cancer Lett. 2008;259(2):156-64. doi: 10.1016/j.canlet.2007.10.006.

28. Shabbeer S, Kortenhorst MS, Kachhap S, Galloway N, Rodriguez R, Carducci MA. Multiple Molecular pathways explain the anti-proliferative effect of valproic acid on prostate cancer cells in vitro and in vivo. Prostate. 2007;67(10):1099110. doi: 10.1002/pros.20587.

29. Grabarska A, Dmoszynska-Graniczka M, Jeleniewicz W, Kielbus M, Nowosadzka E, Rivero-Muller A, et al. Valproic acid suppresses growth and enhances cisplatin cytotoxicity to larynx cancer cells. Head Neck Oncol. 2014;6(1):7. 